\title{
Book Typography and the Contract of Literacy
}

KAY AMERT

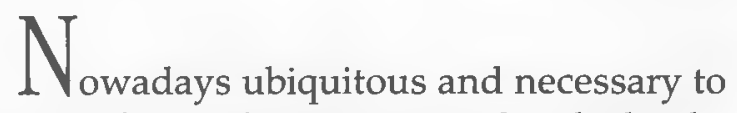
our lives, typographic letterforms also are essential to the books that give us access to the experiences and thoughts of others, in the process permitting us to expand and augment and clarify our own. We make our acquaintance with letterforms as children, and the acquisition of literacy creates what the Swiss typographer Jan Tschichold thought of as a kind of contract, one that is "more cohesive and more difficult to extinguish than any other." 1

Tschichold noted of the typographer's side of this contract that "the art of good typography is eminently logical. It differs from all other art forms in that a substantial portion of the inherent logic is accessible for verification by lay persons." 2 What is meant by this is that most of us recognize a decent letterform when we see one, that we are sensitive to the individual personalities of typefaces, that we can distinguish a pleasant page from another that is less inviting, that the types in some books are perused with ease and confidence, while others induce halting and seem to resist us as we read.

This is part of what makes the art of typography as rich and humane and deep as it is. All who practice it seriously are aware of these lovely connections as they construct words from letters and give shape to the pages that make up books.

\footnotetext{
${ }^{1} J a n$ Tschichold, The Form of the Book, Essays on the Morality of Good Design, (Vancouver, British Columbia: Hartley \& Marks, 1991), p. 13.

${ }^{2}$ Ibid., p. 6.
} 
This essay offers a glimpse of how typographers think about their art. It focuses on four interesting points of agreement about the essential liveliness of letterforms, their simultaneous quiescence on the page, the role of proportion in typographic design, and the importance of clarity in the comprehension of texts. It is drawn with gratitude from the essays and books of a dozen of the most eminent twentieth century writers on typography. It is offered as food for thought for the avid general reader of printed books.

\section{Liveliness}

While most of us think of letters as inanimate forms that serve as transport for words, for typographers, letters have both anima and vigor: they are alive. One factor that has contributed to this understanding is the resurgence of interest in the vital art of calligraphy. Although they may not themselves be calligraphers, most typographers are now acquainted with the sparkling, dark path of the pen as it moves over paper, with the intriguing differences that individuate each calligraphic letter, and with the distinct and recognizable identity of any of the forms drawn by a skillful calligrapher. Even Hermann Zapf, one of the most accomplished and successful type designers of our era, has admitted that despite his long devotion to type design, "my love is still with the broad-edged pen." 3

For other typographers, the vigor of typographical letterforms originates in the hands of the artisans who produced types by traditional means. The distinguished printer Harry Duncan, for example, argues in an essay on "The Permanence of Books" that the "disciplined manipulations" of handicraft "shape tradition itself," historically permitting letterforms both to respond to the sensibility of an age, and to shape it. Duncan worries that the transition to new technological means for type

${ }^{3}$ Hermann Zapf, Hermann Zapf and His Design Philosophy, (Chicago: Society of Typographic Arts, 1987), p. 12. 
design might enervate letterforms. For literature, he argues, such neglect "may be as pernicious in its way as the general indifference of readers." 4

Yet other writers have sought to actualize the metaphor. For example, the Canadian typographer Robert Bringhurst's recent book on typographic style includes among its first principles the assertion that "letters have a life and dignity of their own." As a poet as well as a typographer, Bringhurst offers two similes and a metaphor to explain this principle: "In a badly designed book, the letters mill and stand like starving horses in their field. In a book designed by rote, they sit like stale bread and mutton on the page. In a well-made book, . . . the letters are alive. They dance in their seats. Sometimes they rise and dance in the margins and aisles." 5

\section{Quiescence}

While such liveliness and vitality are highly valued by typographers, in an interesting paradox, so is the quality of quiescence. Jan Tschichold characterized this as the "unalterable effect" produced by perfect book typography. For Tschichold, "perfect typography depends on perfect harmony between all of its elements." To achieve it, typographers must discover the "affinities" which are "hidden in any and all parts" of a typographical page. ${ }^{6}$

The Canadian typographer Carl Dair agreed, commenting that a good book page "is quiet and demands of the reader no visual or intellectual effort to absorb the text. ${ }^{17}$ Dair thought that this effect and others achieved in typographical problemsolving are accomplished in the process of the integration of the typographical structure. Dair was further convinced that the problem of typographic integration resembled that encoun-

${ }^{4}$ Harry Duncan, Doors of Perception, Essays in Book Typography, (Austin: W. Thomas Taylor, 1987), p. 95.

${ }^{5}$ Robert Bringhurst, The Elements of Typographic Style, (Vancouver, British Columbia: Hartley \& Marks, 1992), p. 19.

${ }^{6}$ Tschichold, The Form of the Book, p. 6. 108.

${ }^{7}$ Carl Dair, Design with Type, (Toronto: University of Toronto Press, 1967), p 
tered by architects in resolving and relating the myriad details of three-dimensional architectural structures.

The Belgian typographer Fernand Baudin has recently proposed that the sort of graphic harmony discussed by Jan Tschichold, as well as the integration of structure important to Carl Dair result from the application of a "common visual logic" in the process of typographic design. For Baudin, this logic governs "the rhythm of the writing hand" and produces "coherence in the visual editing of the text matter." 8

\section{Proportion}

The sort of visual logic that Fernand Baudin describes is expressed in typography in part through the exercise of proportion. While classical in origin, interest in proportion remained strong enough through the medieval era to provide a basis for the Renaissance reclamation of Euclidian geometry and other knowledge fundamental to an understanding of proportion. Modern typographers have in turn reclaimed a sense of how to use proportion in letterform construction, in the creation of page shapes, margination and in other applications.

Yet beyond the general agreement on its importance, there are intriguing differences among typographers on the approach to proportion. Some delight in its numerical attributes, while others reject calculation and math. The English typographer Eric Gill, for instance, thought that good proportions for books originated in what he called a "physical reasonableness." formed a measure that suggests book sizes and shapes and such things as the relations among the widths of page margins.

The American book designer Bruce Rogers considered proportion "the most important element of beauty in bookmaking," and found a thousand uses for it in his work. ${ }^{10}$ Rogers wrote of the subtle relations of such things as letter shapes and

${ }^{8}$ Fernand Baudin, How Typography Works (and why it is important), (New York: Design Press, n.d.), p. 23.

${ }^{9}$ Eric Gill, An Essay on Typography, (Boston: David R. Godine, 1988), p. 108.

${ }^{10}$ Bruce Rogers, Paragraphs on Printing, (New York: Dover, 1979), p. 22. 
page shape, letter widths and word space increments, of text area and page area. At the same time he thought "mechanical perfection" to be "inimical" to art: typographers should be artists and not engineers.

Despite his commitment to a modernist aesthetic, the Swiss typographer Emil Ruder also argued against a rigid or mechanical application of proportion in typography. "No system of ratios, however ingenious, can relieve the typographer of deciding how one value should be related to another." 11 Ruder thought that the well-spring of sound proportion lay in feeling and intuition alone. In creating shapes and delimiting spaces for letterforms, typographers must intuitively gauge the rhythms and the kinds of harmony that such shapes and spaces will create.

\section{Clarity}

Finally, there is consensus among typographers on the nature of the ideal reading experience for the long texts that are embodied in books. The simultaneous liveliness and quiescence of book pages, achieved in part through the exercise of proportion, succeed only when they produce an optical dynamic that fosters clarity in the act of reading. Clarity is the prerequisite of comprehension.

Perhaps the most forceful articulation of this principle to be found in the literature comes from the English typographer Stanley Morison. In his essay, "First Principles of Typography," Morison said that "any disposition of printing material which, whatever the intention, has the effect of coming between author and reader is wrong." 12 Morison added that "in all permanent forms of typography, whether publicly or privately printed, the typographer's only purpose is to express, not himself, but his author."13 1981), p. 88.

${ }^{11}$ Emil Ruder, Typography, A Manual of Design, (New York: Hastings House,

${ }^{12}$ Stanley Morison, First Principles of Typography, (Cambridge: Cambridge University Press, 1967), p. 5.

${ }^{13}$ Ibid., p. 15. 
Beatrice Warde put it more prettily when she offered her now-famous metaphor of the crystal goblet. Typography, she argued, needs to be transparent in order to fully reveal the qualities of the "vintage of the human mind." A transparent goblet is preferable to any other because "everything about it is calculated to reveal rather than to hide the beautiful thing which it was meant to contain." 14

Elsewhere in the literature on typography, such words as simplicity, solidity and orderliness surface time and time again as writers attempt to define the requisite typographical groundwork for the clarity that facilitates comprehension. Typographers are glad to discover it wherever they can, as had the American printer Daniel Berkeley Updike when he said of the Italian printing of the fifteenth and early sixteenth centuries: "There is about it a sanity, a lucidity, and a severity."15

Stanley Morison agreed, closing his essay on "First Principles of Typography" with this precis of the meaning of tradition in typography: "Tradition, therefore, is another word for unanimity about fundamentals which has been brought into being by the trials, errors and corrections of many centuries. Experientia docet."16

\footnotetext{
${ }^{14}$ Beatrice Warde. "Printing Should Be Invisible," in Books and Printing, (Cleveland: World Publishing Company, 1963), p. 109.

${ }^{15}$ Daniel Berkeley Updike, In the Day's Work, (Cambridge, Massachusetts: Harvard University Press, 1924), p. 42.

${ }^{16}$ Morison, First Principles of Typography, p. 24.
} 